\title{
A Multi-walled Carbon Nanotube Electrode for Renewable Energy Storage: An Experimental Investigation on Cyclic Charging and Discharging
}

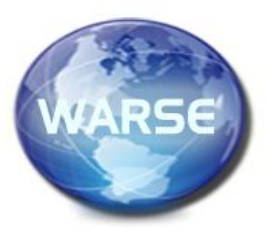

\author{
Diksha Kapoor ${ }^{1}$, Amandeep Singh Oberoi ${ }^{2}$,Parag Nijhawan ${ }^{3^{*}}$ \\ ${ }^{1,2,3}$ Thapar Institute of Engineering and Technology, Patiala, India \\ 1dixakapoormail@gmail.com \\ 2oberoi@thapar.edu \\ 3parag.nijhawan@rediffmail.com
}

\begin{abstract}
The growth and development of mankind is directly dependent on adoption of renewable energy sources. To meet the continuous demand of energy surplus energy generated can be stored in the form of hydrogen. In this paper, cyclic charging and discharging of multi walled carbon nano tube (MWCNT) electrode integrated proton battery has been discussed. A proton battery is a modified reversible polymer electrolyte membrane fuel cell (PEMFC) which has been thought of as an alternative to the lithium based batteries to store the energy. This energy storage in turn, improves the reliability of the intermittently available renewable energy sources. Actually, lithium based batteries are not pollution free, and cause water and air pollution. The analysis ascertains that maximum of $81.26 \mathrm{mAhg}^{-1}$ can be stored while charging or electrolyser mode of proton battery and energy extracted while discharging or fuel cell mode is $1.476 \mathrm{mAhg}^{-1}$. Total four charging and discharging cycles were carried out to assess the performance of proton battery.
\end{abstract}

Key words: -Polymer electrolyte membrane fuel cell (PEMFC), multi walled carbon nano tube (MWCNT), proton battery, renewable energy storage

\section{INTRODUCTION}

With the development of human civilization, energy has been the main asset to distinguish developed and developing countries. The supply of energy is being met by use of fossil fuels which are non replenish able resources. These sources are cause of environment degradation in the form of green house gases and pollution. The conventional resources can be replaced with non-conventional resources such as solar, wind and tidal energy. But the intermittent nature of non-conventional sources is the major drawback which can be overcome with the help of batteries such as lead acid, nickelcadmium $(\mathrm{Ni} / \mathrm{Cd})$, nickel-metal hydride $(\mathrm{Ni} / \mathrm{MH})$, lithiumion polymer and lithium ion [1-2]. Lead acid batteries have short life, inadequate energy density, high maintenance whereas Nickel cadmium have memory effect and in case of lithium ion battery require automotive application along with a sophisticated voltage management system to prolong life and preventing thermal runaway [2]. Nowadays, generally, lithium based batteries are being used, and the cost of recycling these batteries is approximately five times more than the manufacturing cost of a fresh battery. That is why, all the battery manufacturing companies are just extracting fresh lithium from the earth, and unknowingly converting the earth into a lithium dump.

The recycling cost of batteries makes it uneconomic for use, so there is requirement of alternate storage system. Hydrogen can serve as one of the best form of storage system in place of batteries. The stored hydrogen can be retrieved in the form of electricity and water by the help of fuel cell. Hydrogen storage can be done in the form of solid-state, liquid or gaseous form. In case of liquid and gaseous form, extra energy is required in storage, therefore, solid-state storage has gathered maximum interest by researchers. As a step towards the storage of hydrogen in solid state, unitized regenerative fuel cell (URFC) was introduced by Andrews and Bahaman in 2015[3]. This system had limitations such as dependency on gas storage and exposed to energy expenditure which were overcome with modified URFC introduced by Professor John Andrew and Saeed Seif Mohammadi in year 2015. Modified URFC was called as proton battery $[4,5]$ which can run as electrolyses to generate hydrogen and as fuel cell, to generated electricity along water. Initial research work was done on metal hydride $\mathrm{AB}_{5}$ electrode to store hydrogen [6]. These metal hydrides were soon replaced by carbon because they were heavy and costly. The main reason behind carbon considered in further work is: ease of availability, internal pore surface area and light weight [7]. According to the literature [7-11], multi walled carbon nano tube (MWCNT) is form of carbon with major potential of hydrogen storage which is yet to be reported in as part of proton battery.

This paper aims to assess the performance of electrochemical hydrogen storage capacity of proton battery integrated with MWCNT during cyclic charging and discharging.

\section{WORKING}

The proton battery experimental setup has been shown in Fig. 1 that includes three outlets: one on oxygen side and two on hydrogen side. These vents are used for collection and retrieval of gas during charging and discharging process. The setup also contains a variable $30 \mathrm{~V}$ DC source which supplies power during charging or electrolysis mode of proton battery. To measure the potential across and current through the battery, two multimerters are used. 
Galvanostatic charging is performed by keeping potential initially at $1.5 \mathrm{~V}$ and raising it by $0.1 \mathrm{~V}$ in an intervals of half an hour. Water gets split into $\mathrm{H}^{+}$, oxygen and electron under the influence of catalyst and electrical potential. As the potential rises, the current through the battery increases along with gases liberation. The charging process is stopped when rapid evolution of hydrogen gas is noticed.

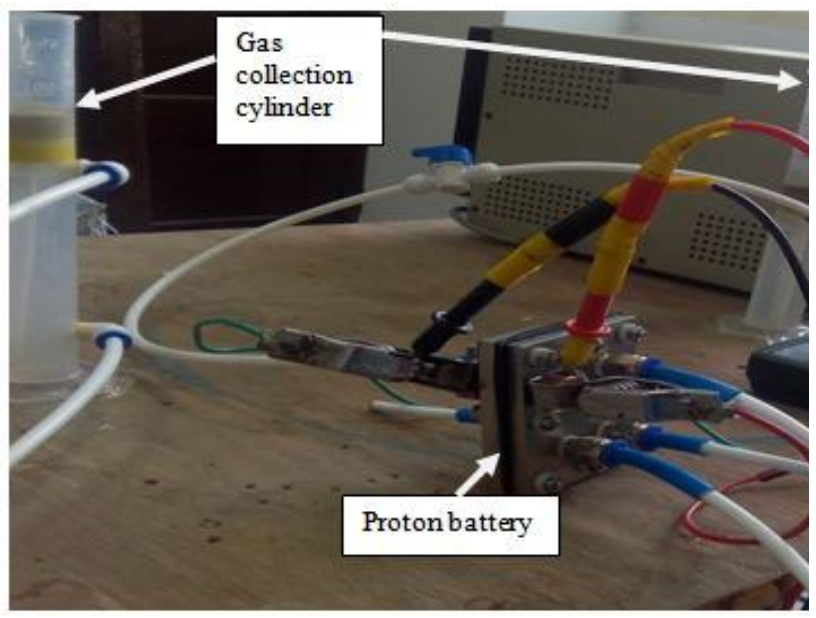

Figure 1: Experimental setup of proton battery or modified URFC.[12]

The produced gases are moved out of the cell and collected. $\mathrm{H}^{+}$ions pass polymer membrane and electrons travel via an external electrical circuit. At cathode, hydrogen ions emerging out of polymer membrane create bonds as these enter porous multi walled carbon nano tube electrode. $\mathrm{H}^{+}$gets adsorbed in MWCNT via chemisorptions or physisorption.

During discharging process, the set up was made to rest for an hour. Discharging of cell was performed by connecting electrical load across the cell. The potential difference was sufficient to break weak chemical bonds, and liberate $\mathrm{H}^{+}$ion. The process taking place during fuel cell and electrolyser mode of proton battery has been shown in the Fig. 2 .

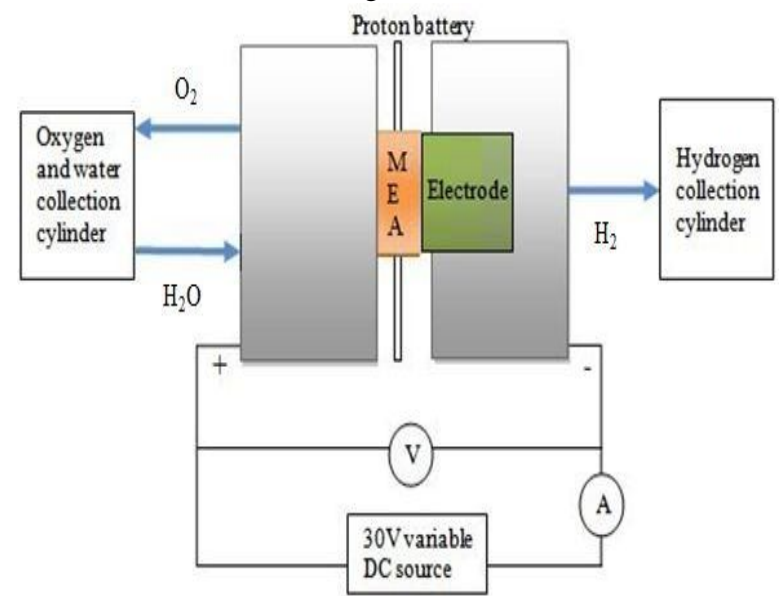

(a)

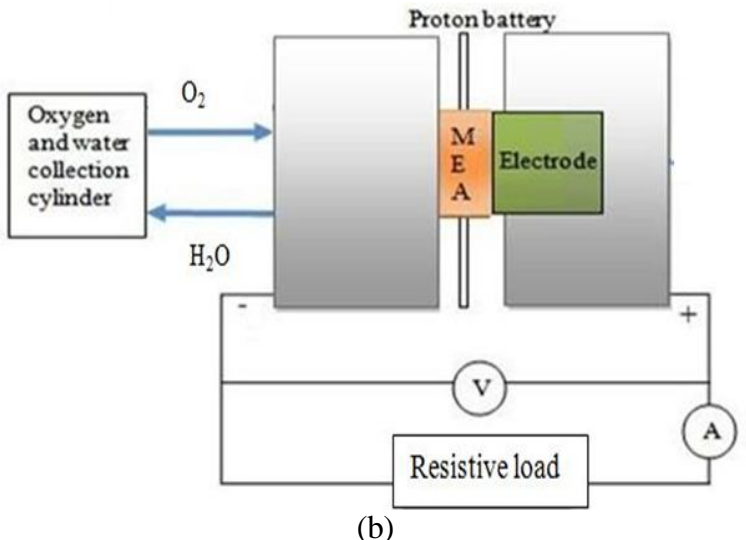

Figure 2 (a)" Schematic diagram of electrolysis mode of proton battery; (b) Schematic diagram of fuel cell mode of proton battery[12]

\section{RESULTS}

The charging and discharging process was carried out for four cycles. It was observed that cut-in voltage lie between 1.7 to $1.9 \mathrm{~V}$. While performing electrolysis, the potential was increased by $0.1 \mathrm{~V}$ in an interval of half an hour till there was rapid evolution of hydrogen gas. The rapid evolution of hydrogen gas indicate that all the pores of MWCNT electrode are filled, and the no more adsorption of hydrogen gas can take place. The electrolysis mode was stopped at $2.5 \mathrm{~V}$. The voltage versus current shows a linear relationship. The hydrogen evolution increases with time as shown in Fig.3. The gas evolution took place form 30 minutes to 2.5 hours in first three cycles where as in the fourth cycle, the evolution of gas was taking place upto 3 hours. The hydrogen gas produced during this interval varies from $30 \mathrm{ml}$ to $38 \mathrm{ml}$.

Hydrogen Vs time for first cycle

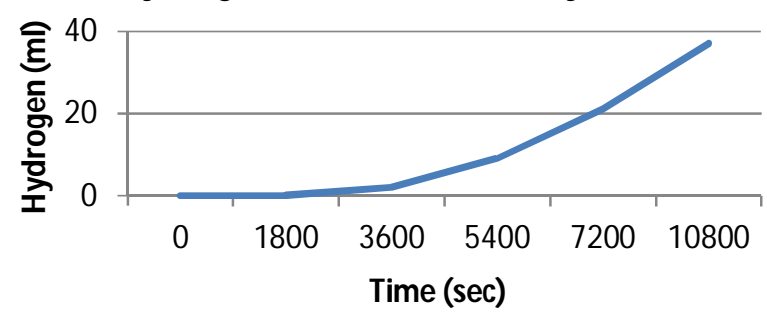

(a)

\section{Hydrogen Vs time for second cycle}

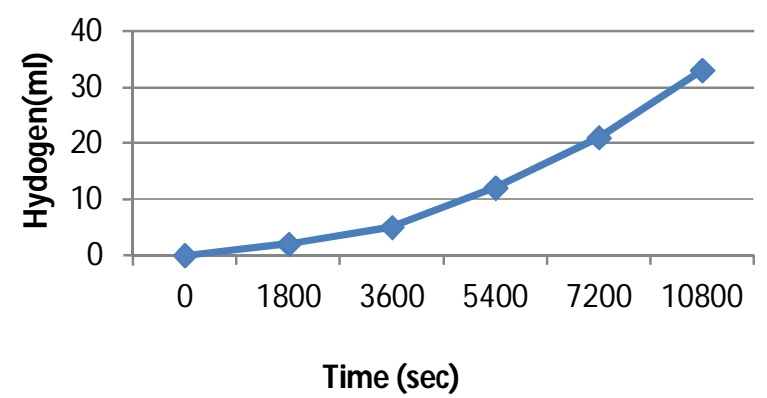

(b) 


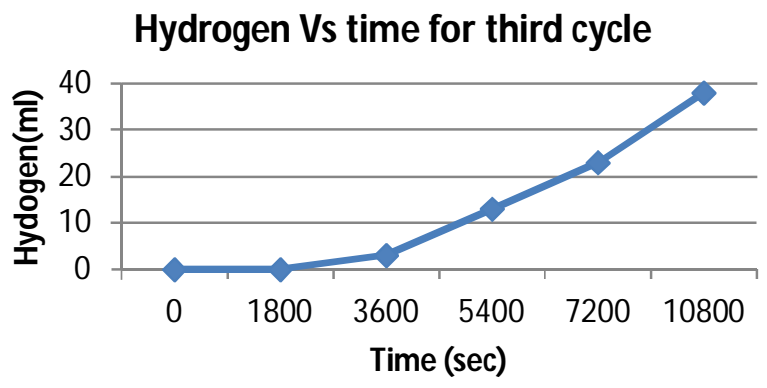

(c)

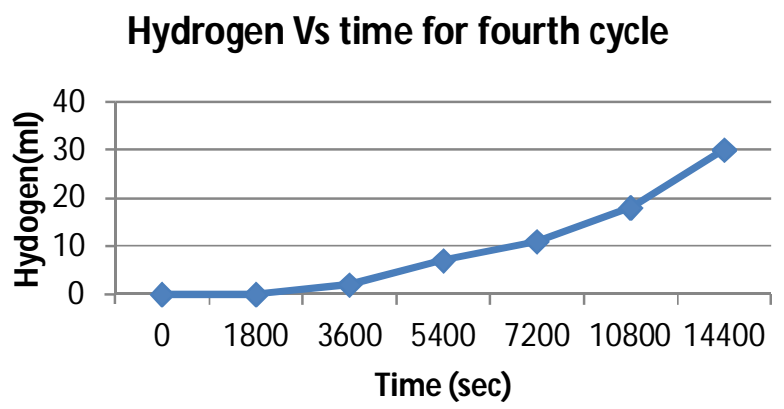

(d)

Figure 3: Graph representing relation between hydrogen gas produced and time during charging of proton battery.

The oxygen gas produced with respect to time in case of electrolyser mode of proton battery during four cycles when subjected to cut-in voltage of $1.7 \mathrm{Vis}$ shown in Fig.4.Oxygen gas produced was stored in gas collection cylinder. The production of gas increases with rise in voltage. The flow of charge increases with production of oxygen ions which combines together to forming oxygen gas.

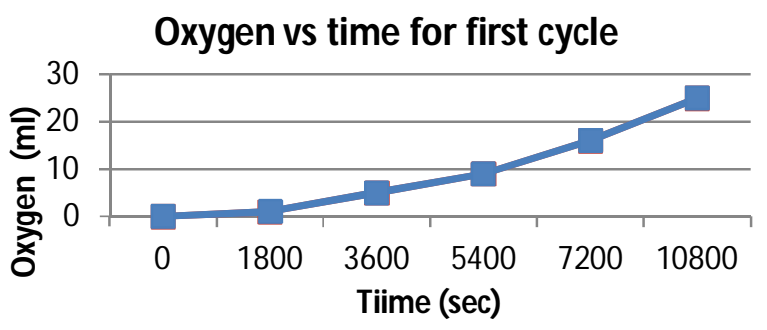

(a)

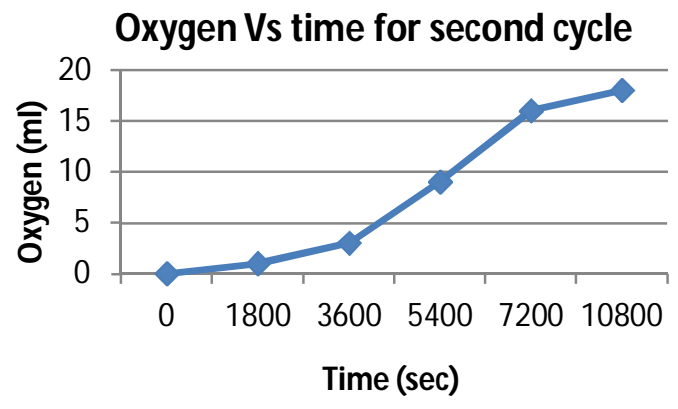

(b)

\section{Oxygen Vs time for third cycle}

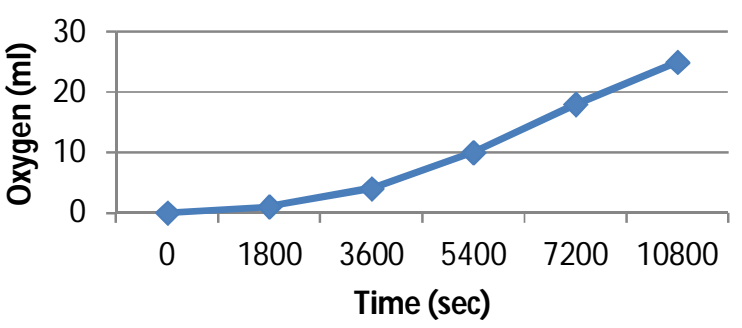

(c)

\section{Oxygen Vs time for fourth cycle}

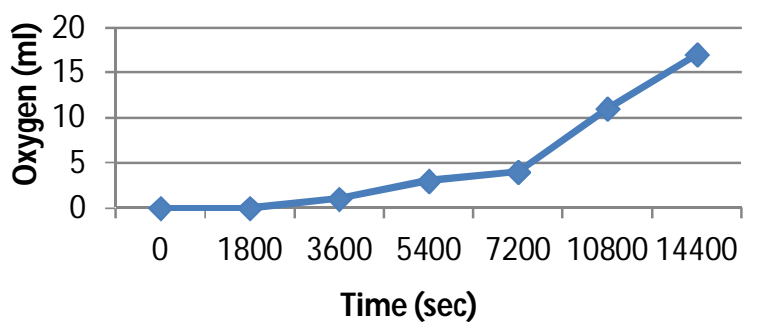

(d)

Figure 4: Graph showing relation between oxygen gas produced with respect to time in case of electrolyser mode of proton battery during four cycles.

The mass percent of hydrogen has been calculated for half hour intervals, and its variation with respect to current is shown in Fig.5.The amount of hydrogen adsorbed in porous MWCNT electrode was calculated by subtracting mass of hydrogen produced with theoretical mass of hydrogen.

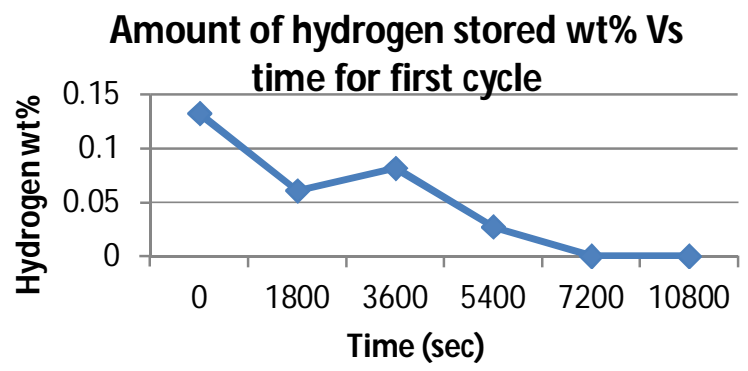

(a)

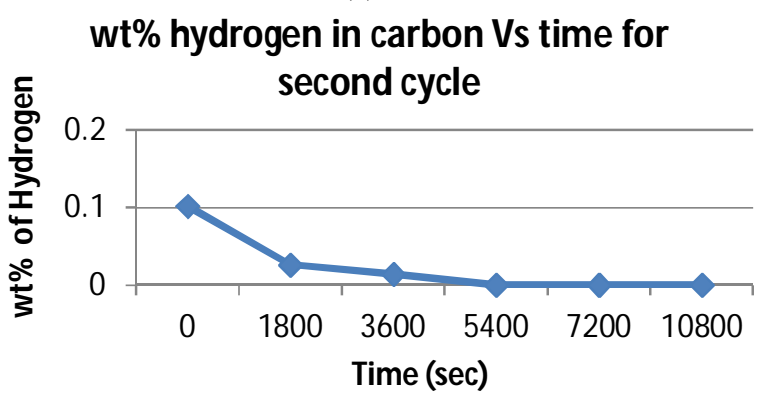

(b) 
Diksha Kapoor et al., International Journal of Advanced Trends in Computer Science and Engineering, 8(3), May - June 2019,513 - 518

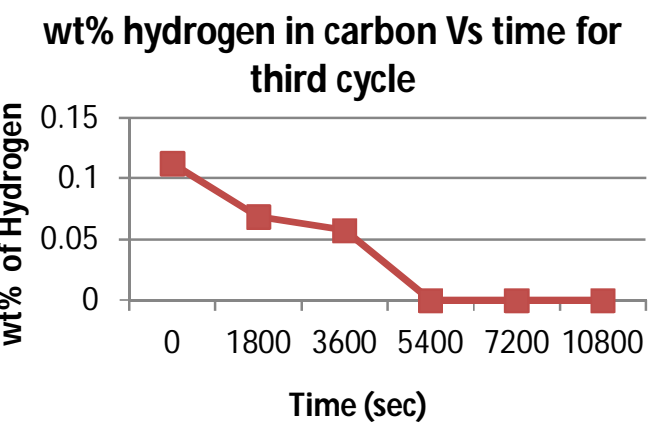

(c)

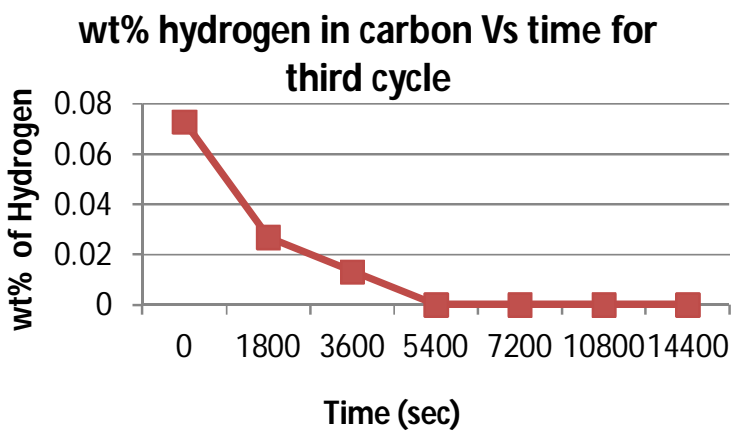

(d)

Figure 5: Graph showing relation of wt $\%$ of hydrogen stored in carbon and voltage during electrolyser mode of proton battery.

From Table 1, it can be interpreted that with the increase in current, electrochemical hydrogen storage decreases in the MWCNT electrode. The wt $\%$ of hydrogen has been calculated using Faraday's law. The amount of hydrogen that did not came out from proton battery was considered to be adsorbed inside electrode presuming no loses.

Table 1(a) : Graph showing relation between wt $\%$ of hydrogen stored in carbon and current during first cycle charging of modified URFC or proton battery

\begin{tabular}{|l|l|l|}
\hline S.No. & Current(mA) & $\begin{array}{l}\text { Wt\% } \\
\text { hydrogen in } \\
\text { carbon }\end{array}$ \\
\hline 1 & 33 & 0.132528 \\
\hline 2 & 15.1 & 0.060685 \\
\hline 3 & 29.2 & 0.081501 \\
\hline 4 & 46.9 & 0.027246 \\
\hline 5 & 69.2 & 0 \\
\hline 6 & 89.2 & 0 \\
\hline
\end{tabular}

Table 1(b): Graph showing relation between wt $\%$ of hydrogen stored in carbon and current during second cycle charging of modified URFC or proton battery

\begin{tabular}{|l|l|l|}
\hline S.No. & Current $(\mathrm{mA})$ & $\begin{array}{l}\text { Wt\% of hydrogen } \\
\text { in carbon }\end{array}$ \\
\hline 1 & 31.6 & 0.101556 \\
\hline 2 & 17 & 0.025999 \\
\hline 3 & 26.6 & 0.013862 \\
\hline 4 & 44.4 & 0 \\
\hline 5 & 59.6 & 0 \\
\hline 6 & 77.6 & 0 \\
\hline
\end{tabular}

Table 1(c): Graph showing relation between wt $\%$ of hydrogen stored in carbon and current during third cycle charging of modified URFC or proton battery

\begin{tabular}{|l|l|ll|}
\hline S.No. & Current $(\mathrm{mA})$ & $\begin{array}{l}\text { Wt\% } \\
\text { hydrogen } \\
\text { carbon }\end{array}$ & $\begin{array}{l}\text { of } \\
\text { in }\end{array}$ \\
\hline 1 & 28 & 0.11247 \\
\hline 2 & 17.1 & 0.06872 \\
\hline 3 & 27.7 & 0.05758 \\
\hline 4 & 49.7 & 0 \\
\hline 5 & 79.7 & 0 \\
\hline 6 & 96.6 & 0 \\
\hline
\end{tabular}

Table 1(d) :Graph showing relation between wt $\%$ of hydrogen stored in carbon and current during third cycle charging of modified URFC or proton battery

\begin{tabular}{|l|l|ll|}
\hline S.No. & Current (mA) & $\begin{array}{l}\text { Wt\% } \\
\text { hydrogen } \\
\text { carbon }\end{array}$ & $\begin{array}{l}\text { of } \\
\text { in }\end{array}$ \\
\hline 1 & 18.2 & 0.07313 \\
\hline 2 & 6.7 & 0.02694 \\
\hline 3 & 12.2 & 0.0132 \\
\hline 4 & 38.3 & 0 \\
\hline 5 & 57.4 & 0 \\
\hline 6 & 86.8 & 0 \\
\hline
\end{tabular}

During electrolysis, the value of current increased form $33 \mathrm{~mA}$ to $89.2 \mathrm{~mA}$ during first cycle where as in second cycle current range from $31.6 \mathrm{~mA}$ to $77.6 \mathrm{~mA}$. In the third cycle current varies from 28 to $96.6 \mathrm{~mA}$ and in last cycle it changes from 18.2 to $86.8 \mathrm{~mA}$.

The wt $\%$ of hydrogen in carbon versus time has been depicted in Fig.6. This Figure shows that the thewt \% of hydrogen decreases as there is increase in the time. At initial stage, the wt $\%$ of hydrogen is highest and it decreases with the increase in the current.

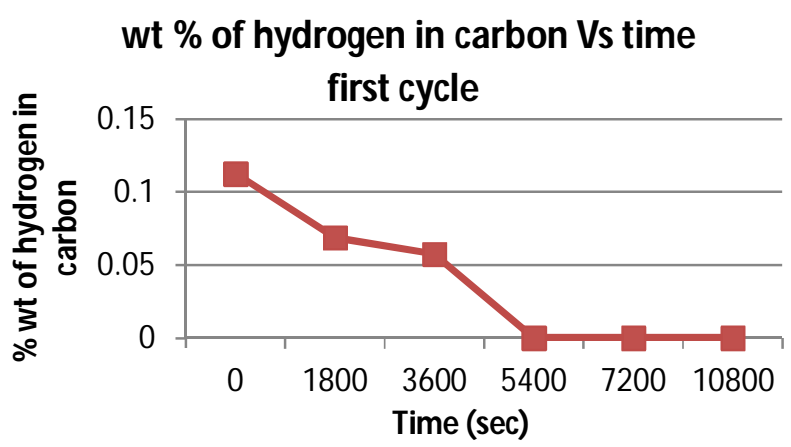

(a) 


\section{wt $\%$ of hydrogen in cabron Vs time second cycle}

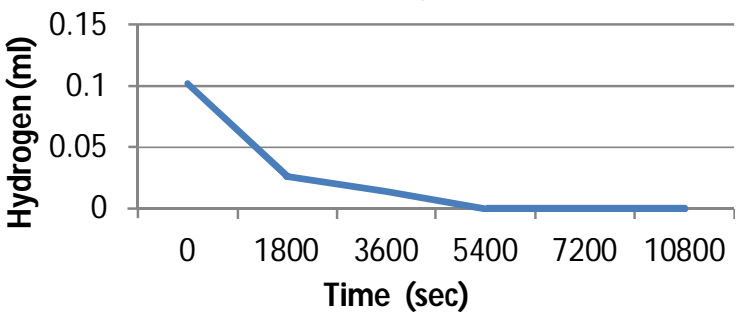

(b)

wt $\%$ of hydrogen in cabron Vs time third cycle

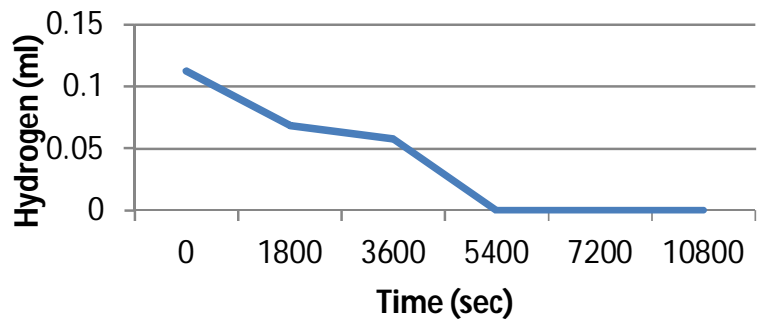

(c)

wt $\%$ of hydrogen in cabron Vs time

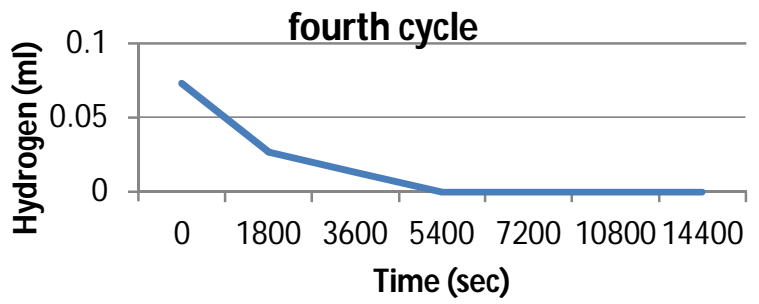

(d)

Figure 6: Graph between wt $\%$ of hydrogen stored in carbon and time during charging of proton battery.

During fuel cell mode or discharging mode, the voltage and current curves have been observed Maximum 1.29V has been reached in third cycle and was discharged with in $30 \mathrm{~min}$.

The relation between wt $\%$ of hydrogen that got released during the discharging or fuel cell mode of proton battery for first four cycles has been shown in Fig.7. The discharging cycle gets completed in 20 to $30 \mathrm{~min}$. The battery was connected to a resistive load of $200 \Omega$ for the discharging process.

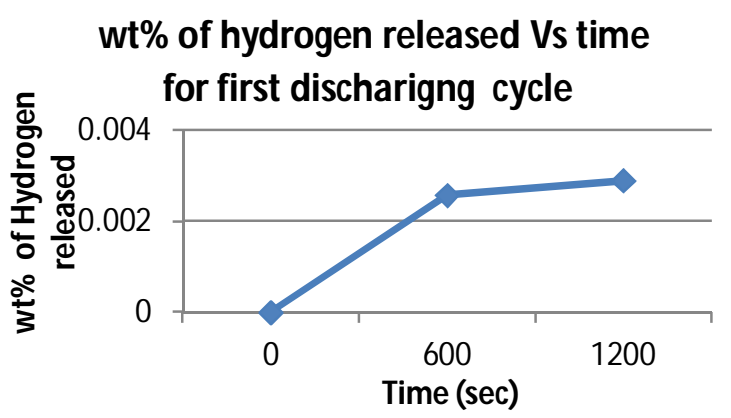

(a)

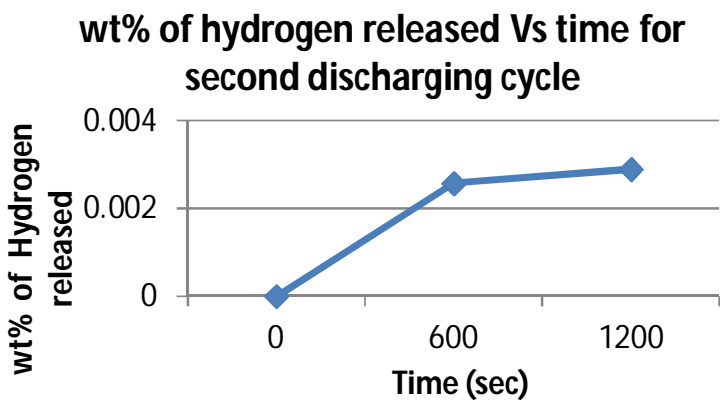

(b)

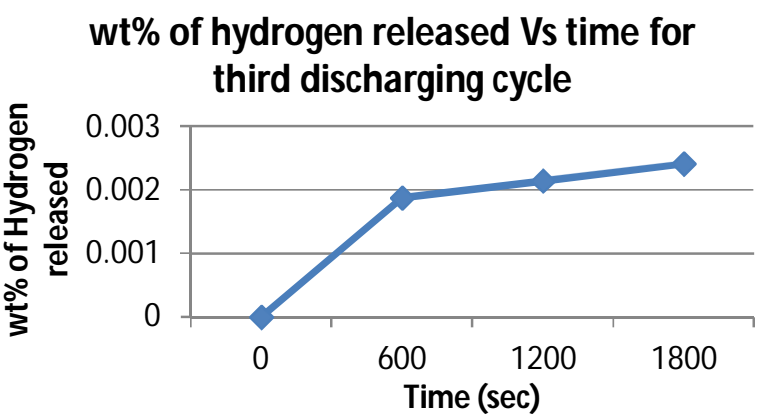

(c)

$w t \%$ of hydrogen released Vs time for

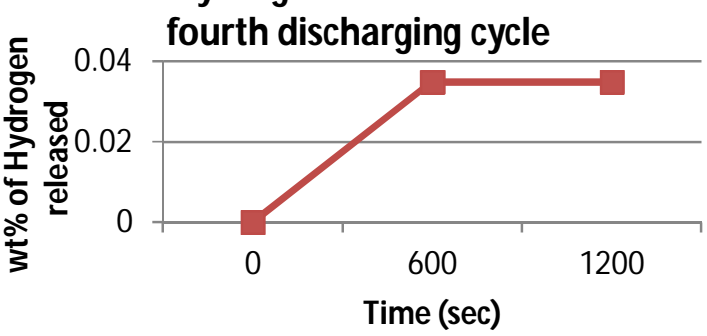

(d)

Figure 7: Graph showing relation between wt\% of hydrogen released and time during fuel cell mode of proton battery.

The amount of hydrogen adsorption and desorption during first four cycles of electrolyser and fuel cell modes has been summed up in Table 2. During electrolyser mode, the hydrogen stored in porous multi walled carbon nano tube was retrieved in fuel cell mode.

Table 2: Capacity of stored $\mathrm{mAhg}^{-1}$ of hydrogen for electrolyser and fuel cell mode of proton battery

\begin{tabular}{|l|l|l|}
\hline Cycle & $\begin{array}{l}\mathrm{mAhg}^{-1} \text { Electrolyser } \\
\text { mode }\end{array}$ & $\begin{array}{l}\mathrm{mAhg}^{-1} \\
\text { cell mode }\end{array}$ \\
\hline 1 & 81.529 & 1.476 \\
\hline 2 & 38.182 & 1.049 \\
\hline 3 & 64.466 & 0.629 \\
\hline 4 & 30.583 & 0.188 \\
\hline
\end{tabular}

\section{DISCUSSION}

From chemical composition of water, it can be stated that after dissociation, two $\mathrm{H}^{+}$and one $\mathrm{O}^{2-}$ are released Ideally, hydrogen produced during the electrolysis should be twice that of oxygen but during experiment, it was found that amount of hydrogen produced is less presuming no leakage. Hydrogen got adsorbed in the MWCNT electrode by physisorption and chemisorptions, 
while few atoms form hydrogen gas that gets collected in collection cylinder. During charging, it was found that maximum $0.301 \mathrm{wt} \%$ of hydrogen was stored in multi walled carbon nano tube which is equivalent to $81.5293 \mathrm{mAhg}^{-1}$, while maximum discharged wt $\%$ of hydrogen was $0.005 \mathrm{wt} \%$ which is equivalent to $1.47 \mathrm{mAhg}^{-1}$ [13].From the results, it can be stated that at low current, the gas formation was less and hydrogen adsorption was more. Current controlled dissociation is required in order to suppress gas formation and enhance adsorption of hydrogen in MWCNT.

\section{CONCLUSION}

It was demonstrated experimentally that MWCNT has capacity to store hydrogen when placed in proton battery. Though the $\mathrm{mAhg}^{-1}$ retrieved through fuel cell or discharging mode was quite less as compared to electrolyser mode. Not all stored hydrogen was able to come out therefore, the results form the foundation to ascertain the life cycle of proposed proton battery. The proposed proton battery can certainly replace the lithium based batteries which do not emit any harmful byproducts. The only by-products of the proposed proton battery are oxygen, hydrogen and pure water which are pollution free, and also have commercial value.So, it can be safely concluded that the integration of proton battery with the renewable energy sources is a fully sustainable solution, that can enhance the reliability of the renewable energy sources.

\section{REFERENCES}

[1] S.G. Chalk and J.F.Miller, "Key challenges and recent progress in batteries, fuel cells, and hydrogen storage for clean energy systems," Journal of Power Sources, vol. 159, no. 1, pp.73-80, 2006. https://doi.org/10.1016/j.jpowsour.2006.04.058

[2] A.C.R.Teixeira, D.L.da Silva, L.D.V.B.M.Neto, A.S.A.C. Diniz and J.R.Sodré, "A review on electric vehicles and their interaction with smart grids: the case of Brazil," Clean Technologies and Environmental Policy, vol. 17, no. 4, pp.841-857, 2015.

https://doi.org/10.1007/s10098-014-0865-x

[3] J.Dufour, D.P.Serrano, J.L.Galvez, J.Moreno and C.Garcia, "Life cycle assessment of processes for hydrogen production. Environmental feasibility and reduction of greenhouse gases emissions," International journal of hydrogen energy, vol. 34, pp. 1370-1376, 2009. doi: 10.1016/j.ijhydene.2008.11.053..

[4] P.P.Edwards, V.L.Kuznetsov,W.I.F.David and N.P. Brandon, "Hydrogen and fuel cells: towards a sustainable energy future," Energy policy, , vol. 36, pp. 4356-4362, 2008. doi: 10.1016/j.enpol.2008.09.036.

[5] A. Oberoi, P. Nijhawan and P. Singh," A Novel Electrochemical Hydrogen Storage-Based Proton Battery for Renewable Energy Storage," Energies, vol. 12(1), p.82, 2019. doi: 10.3390/en12010082

[6] M.Ali, J.Ekström and M.Lehtonen, "Sizing hydrogen energy storage in consideration of demand response in highly renewable generation power systems," Energies, vol. 11, 1113, 2018. doi:10.3390/en11051113.
[7] M.Rosen, "Energy sustainability: A pragmatic approach and illustrations," Sustainability, vol. 1, pp. 55-80, 2009. doi: 10.3390/su1010055.

[8] L.Gracia, P.Casero, C.Bourasseau, and A.Chabert, "Use of Hydrogen in Off-Grid Locations, a TechnoEconomic Assessment," Energies, vol. 11, 3141, 2018. doi: 10.3390/en11113141.

[9] F.C.Wang, Y.S. Hsiao and Y.Z.Yang, "The Optimization of Hybrid Power Systems with Renewable Energy and Hydrogen Generation," Energies, vol. 11, 1948, 2018. doi: 10.3390/en 11081948 .

[10] F.Zhang andP.Cooke, "Hydrogen and fuel cell development in China: a review," European Planning Studies,vol. 18, pp. 1153-1168, 2010. doi: 10.1080/09654311003791366.

[11] A.Züttel, A.Borgschulte and L.Schlapbach, "Hydrogen as a Future Energy Carrier," Wiley Publications: Hoboken, NJ, USA, 2008; ISBN: 9783527622894. https://doi.org/10.1002/9783527622894

[12] D.Kapoor, A.S. Oberoi and P.Nijhawan, "Hydrogen Production and Subsequent Adsorption/Desorption Process within a Modified Unitized Regenerative Fuel Cell," Processes, vol. 7, no. 4, 238, 2019. https://doi.org/10.3390/pr7040238

[13] K.Babel, D.Janasiak and K.Jurewicz,“ Electrochemical hydrogen storage in activated carbons with different pore structures derived from certain lignocellulose materials," Carbon, vol. 50, pp. 5017-5026, 2012.

https://doi.org/10.1016/j.carbon.2012.06.030 